DOI 10.37882/2223-2982.2020.07.27

\title{
ЗАРУБЕЖНАЯ ПРАКТИКА ОБРАЗОВАНИЯ ДЕТЕЙ КОЧУЮЩИХ КОРЕННЫХ НАРОДОВ
}

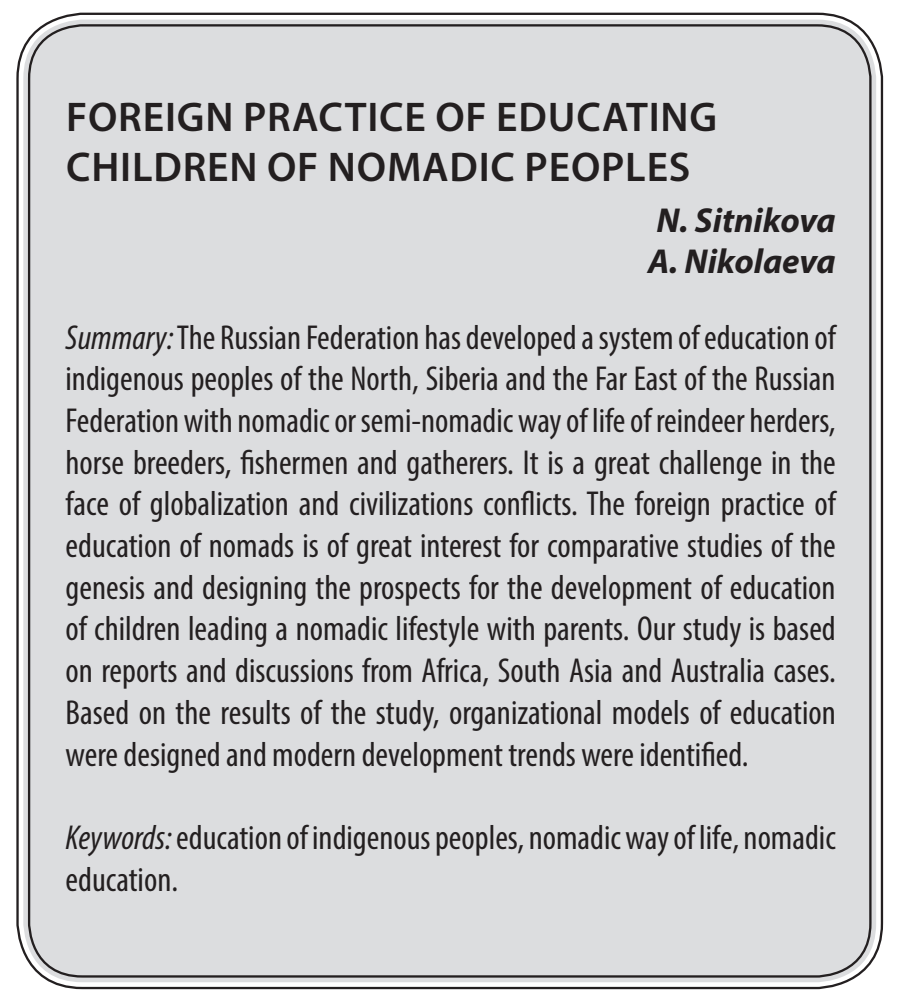

\section{Введение}

$\mathrm{O}$ дним из главных вызовов современности является проблема выработки такой модели образования коренных народов в условиях глобализации, которая бы сохранила цивилизационное многообразие мира наряду с обеспечением права детей на образование и включение в окружающий современный мир. Можно считать парадоксом, что в системах образования на основе стационарных школ и стандартизации содержания образования, сохраняются отдельные примеры кочевого образования, то есть образования, основанного на индивидуальных учебных планах и неформальном образовании в ходе движения с кочевыми семьями в поисках пастбищ для животных.

\section{Материалы и методы}

В ходе работы проведен анализ зарубежного опыта кочевого образования, выявлены общие проблемы и стратегии их решения, разработаны модели организации образования детей, ведущих с родителями кочевой образ жизни. Для апробации разработанных моделей, автором применены методы научного и практического исследования: обзор научной литературы по проблеме исследования, обсуждение на дискуссионных площад-
Ситникова Наталья Васильевна

руководитель чентра кочевого образования, ФГБНУ «НИИ национальных школ Республики Саха (Якутия)», г. Якутск nsitni@rambler.ru

Николаева Алла Дмитриевна Д.п.н., професссор, ФГАОУ ВО «Северо-Восточный федеральный университет имени М.К. Аммосова»,

2. Якутск

Аннотация: В Российской Федерации сложилась система образования коренных малочисленных народов Севера, Сибири и Дальнего Востока Российской Федерации, ведущих традиционный кочевой и (или) полукочевой образ жизни оленеводов, скотоводов, рыбаков и собирателей. Это серьезный вызов в условиях глобализации и конфликта цивилизаций. Зарубежная практика образования кочевников представляет огромный интерес для сопоставительного исследования генезиса и проектирования перспективы развития образования детей, ведущих с родителями кочевой образ жизни в условиях глобализации. Наше исследование основано на научных сообщениях и дискуссиях вокруг опыта стран Африки, Южной Азии и Австралии. В результате исследования разработаны организационные модели образования и выявлены современные тенденции развития.

Ключевые слова: образование коренных народов, кочевой образ жизни, кочевое образование.

ках и реализация моделей на практике.

Обзор зарубежной практики. В условиях потенциально существующей угрозы «стирания цивилизационных границ, наиболее актуальным из научно-методологических подходов в комплексном изучении человеческих систем представляется цивилизационный" [14, с.670], в большей степени позволяющий отразить социокультурную уникальность каждой системы. Кочевые цивилизации перестают быть архаичным этапом развития миросоздания, выдвигаются на первый план и представляют интерес в научной сфере. Гипотеза А.Дж. Тойнби, высказанная им в в первой половине XX в., о том, что «западная цивилизация, распространившая свои щупальца по всей поверхности земного шара, завершает истребление кочевников» не подтвердилась. Жамбалова С.Г., исследуя проблематику кочевого образа жизни в современном мире, подтверждает на примере монголоязычных народов, кочевников-скотоводов Центральной Азии, что «кочевой образ жизни довольно масштабно существует в современном мире» [9, с.142-149]. Это же отмечают на основе достоверных фактов современные исследователи кочевых цивилизаций Грайворонский В.В., Жуковская Н.Л. [6, с. 249-260; 9, с.247] и другие.

В ответ на вышеуказанные вызовы государства и ко- 
чевые народы предпринимают меры для сохранения кочевого или полукочевого образ жизни, связанного с пасторализмом - культурой скотоводчества как вида экономической деятельности и социокультурной реальности, в рамках которых решаются проблемы доступности общего образования детей, ведущих с родителями традиционный образ жизни.

Кочевой или полукочевой образ жизни широко распространен в странах Африки, Востока и Азии, имеет свои характеристики и связан с уникальной кочевой культурой, главной особенностью которой является движение (перемещение) скотоводов за скотом, который, в свою очередь, двигается в поисках лучших пастбищ. Миллионы кочевых скотоводов вовлечены в хозяйственный процесс и традиционные промыслы, являющиеся основой кочевого уклада жизни. Исследователи отмечают также кочевые и полукочевые народы, занятые рыбной ловлей, охотой и собирательством.

Саверио Краетли, исследователь кочевых народов, член Международного союза антропологических и этнологических наук (IUAES) (2001), подчеркивает, что миллионы детей кочевников остаются вне системы образования [10, с. 67-72]. С одной стороны образование для кочевников должно соответствовать общепринятому пониманию базового образования как фундаментальной потребности. С другой стороны, в качестве необходимого условия существования скотоводы каждый день демонстрируют высокие уровни индивидуальных и социальных навыков. Вместе с тем «образовательные программы, по-видимому, противостоят кочевой культуре на всех уровнях» (Краетли, там же).

Анита Шарма (2011) [4, с. 1-51], исследователь кочевых народов стран Южной Азии, подтверждает, что в Индии, Непале остро стоит проблема доступности образования для кочующих народов. В этих странах разработали альтернативные подходы к образованию и формам обучения и специальные структуры для ресурсной поддержки образования детей кочевников. Вместе с тем Шарма отмечает, что часто кочевники «остаются невидимыми для государств» $(4$, с. 37), они не выделяются в статистике.

Кочевники-скотоводы, перемещаясь в поисках пищи для своего скота, также нуждаются в доступе к информации о своем здоровье и здоровье своих животных. ДанАмади (2015) отмечает, что "ключевой целью кочевого образования должно быть предоставление кочевникам чувства принадлежности к нации и защиты со стороны конституций своих стран» [3, с.16-21]. Тони Бут (1999) видит «кочевое образование через призму инклюзивного образования» [5, с.164-168], что способствует вовлечению целевых обучающихся в образовательные программы.
Нгьасике, Джон Терия, исследователь кочевых культур скотоводов Кении из Найроби, отмечает, что дошкольное и начальное «образование кочевых народов основано на западных концепциях без учета этнокультурных особенностей и традиционных знаний, местных культурных концепций, ценностей развития, практики воспитания детей и практических повседневных реалий обучения детей посредством участия в жизни общины и ученичества в контексте семейных обычаев, опыта общины и деятельности по экономическому выживанию» $[11,19-46]$.

Анализ проблем, которые встречают государства в своем стремлении включить кочевые народы, как представителей кочевой цивилизации, в общегосударственные процессы, показывает:

- разные подходы к целеполаганию, несогласованность целевых установок для кочевого образования;

- несоответствие требований формального общего образования потребностям кочевников, в частности, традиционные знания и родные языки не включаются в образовательные программы;

- отсутствие программ профессионального образования для жизни вне кочевья и возможностей для получения среднего или высшего профессионального образования;

- слабую инклюзию кочевников в общество и общегосударственные процессы;

- проблемы, связанные с повышением кадрового потенциала для кочевого образования.

В Нигерии, Кении и других государствах Африки, Иране, Сирии, Индии, Киргизии, Монголии, Австралии, Мадагаскаре и других, где есть кочевые народы, системы образования развиваются в двух направлениях. Также как в России кочевые народы в той или иной мере сохраняют свой уклад и учителя передвигаются вместе с детьми или школы создаются в местах их традиционного проживания, в отдельных странах сильно выражено стремление собрать детей в интернатах для «перекраивания» детей под нужды государства и современного общества.

Анализ зарубежного опыта кочевого образования свидетельствует о широком понимании формальных и содержательных проблем, возникающих при определении понятий «кочевники», «кочевое образование», «мобильная или кочевая школа». Нами отмечаются сходные проблемы в организации обучения детей и подготовке кадров, связанные с мобильностью, потребностью в этнической самореализации кочевых народов, а также с необходимостью участия членов семей в общем труде.

Для преодоления трудностей применяются сходные стратегии. В сфере управления образованием Индии, 
Кении, Нигерии созданы специальные структуры (национальные комиссии, комитеты, ресурсные центры) для регулирования деятельности в сфере образования кочующих народов. Эксперты отмечают целесообразность парципативного участия кочевых общин в управлении образованием создания нормативной базы для обеспечения временного зачисления детей кочевников в стационарные образовательные организации и их инклюзии в общие программы, обеспечивается бесплатное питание обучающихся и выделяются стипендии для малоимущих студентов.

В содержании образования отмечается стремление «помочь приобрести такие навыки, знания и компетенции, чтобы повысить доходы за счет повышения эффективности управления выпасом скота, здоровья животных, использования результатов научных исследований» [12, с.116-117]; «повышение грамотности членов общины, семейной грамотности» [11, с.19-46]; разработка учебных материалов с участием общин в области математики, социальных наук, английского как международного языка, по основам науки и техники [1, с.424]. Исследователи приходят к выводу, что содержание образовательных программ для детей кочевников должно включать практические знания, навыки и компетенции, необходимые для жизни в кочевье и профессиональной ориентации.

В сфере использования информационно-коммуникационных технологий проведены исследования (ЮНЕСКО, 2008) доступности радио и телевидения и приняты специальные меры для их эффективного применения для образования; в Нигерии были организованы специальные студии при центрах кочевого образования для подготовки образовательных программ по радио и телевидению [15].

В сфере материально-технического обеспечения кочевого образования отмечается обеспечение кочевников разборными помещениями, аудиовизуальными учебными пособиями [1, с.21].

Эксперты отмечают значение финансовых обязательств со стороны государства. Производство специфического оборудования, закупка и предоставление необходимых комплектов для кочевого образования должны рассматриваться как неотъемлемая часть программы, и их следует сделать массовыми и привлекательными для обеспечения непрерывности образования детей мобильных кочевников [2, с.407-428].

Анализ зарубежного опыта показывает, что государственные практики, которые игнорируют или пытаются регулировать пространственную популяционную мобильность мобильных культур, имеют сомнительную эффективность и могут еще больше укрепить маргиналь- ный статус мобильных культур. «Мобильные культуры бросают вызов оседлым политическим параметрам, которые связаны с постоянством территории, домовладения и состава семьи» [7].

\section{Результаты}

В результате исследования зарубежной практики образования детей коренных народов, ведущих с родителями кочевой или полукочевой образ жизни, определены модели обеспечения доступности образования:

Модель 1. «Кочевые учителя, реализующие образовательные программы в условиях кочевья». В отдельных странах для устойчивого функционирования этой модели создаются национальные комиссии, государственные структуры управления, а также ресурсные центры с государственным финансированием. В основном, ресурсные центры обеспечивают содержательную часть учебнометодического обеспечения, проводят эксперименты в рамках научных исследований.

Следует особо отметить необходимость подготовки кочевых учителей из числа представителей кочевых общин, выходцев из общин, имеющих опыт кочевой жизни, общий язык и родственные связи.

Модель 2. «Кочевая школа при кочевой общине». Кочевая школа создается при содействии государственных органов власти с целью обеспечения доступности начального образования, а также социальной и государственной инклюзии. Кочевая школа имеет специальное оборудование в виде мобильных помещений (шатров, палаток, яранг, юрт и др.), которые легко собираются и разбираются, то есть, приспособлены к передвижению общины. В отдельных случаях легкие помещения для кочевых школ размещаются по маршруту следования кочевников, в этом случае школа располагается вблизи от основного маршрута и дети имеют возможность посещать школу на кратковременной основе.

В условиях включения детей в производственную деятельность, когда дети вынуждены помогать родителям для обеспечения благополучия семьи, осваивая родовые профессиональные навыки, действуют сезонные кочевые школы. Обучение организуется непосредственно в местах традиционной хозяйственной деятельности или во время перекочевки в населенные пункты (фактории, стойбища). Дополнительное образование в условиях кочевого образа жизни имеет неформальный характер, связано с потребностью приобщения детей к труду скотоводов, оленеводов, рыболовов в процессе совместной деятельности с взрослыми. В кочевых школах возможна реализация программ гражданского воспитания, здорового образа жизни, безопасности, основ экологических знаний и основ экономики. 
Модель 3. «Кочевая школа с дистанционным обучением». В местностях, где есть возможность обеспечить доступность радио - и телевещания, а также интернета организуются специальные центры дистанционного образования и студии образовательных радио- и телепередач с подготовленным персоналом, которые обеспечивают также подготовку кочевников к системе дистанционного образования. В местах традиционного проживания и традиционной хозяйственной деятельности в Монголии и в Австралии отмечается позитивный эффект от привлечения членов общин к организации детей в специально-оборудованных помещениях для прослушивания и (или) интерактивного взаимодействия через информационные технологии по согласованным графикам обучения.

Результаты исследования и проектирования моделей организации образования детей из кочевых семей использованы при разработке методических рекомендаций для организаторов образования детей коренных малочисленных народов Севера, Сибири и Дальнего Востока Российской Федерации в местах традиционного проживания и традиционной хозяйственной деятельности.

\section{ОбсужАение}

В ходе обсуждения отмечены возможности государств и кочевых общин в парципативной работе по образованию детей, обсуждены модели образования детей кочевых народов в странах Африки, Востока и Азии. Отмечено отсутствие официальной статистики по кочевым народам, недостаточное присутствие российского опыта кочевого образования в международном научном пространстве и значительный объем дискуссии в мире по поводу аспектов содержания образования и языков обучения кочевых народов.

\section{Зак^ючение}

По итогам исследования зарубежной практики образования детей коренных народов в странах Африки, Востока и Азии нами отмечены наличие сходных проблем и стратегий включения кочевых культур в современную цивилизационную парадигму. Инновационные экспериментальные проекты и исследования в международной научной среде связаны с глобальным целями тысячелетия и растущим интересом к кочевой культуре и мобильности, как интегральной характеристике образа жизни и личности. Коренные народы, ведущие кочевой и (или) полукочевой образ жизни, занимают особое место в социально-экономической жизни страны и могут внести ощутимый вклад в экономику своих семей и регионов, одновременно представляя особую кочевую цивилизацию.

В настоящее время в системе образования коренных малочисленных народов России происходят значительные изменения, связанные с разграничением полномочий в сфере управления образованием, модернизацией общего образования, углублением процессов демократизации и общественного участия в управлении образованием, национальными проектами, направленными на успех каждого ребенка, доступность и открытость образования. Исходя из вышеизложенного, мы приходим к выводу, что предстоит переосмысление концептуальных подходов и ранее применяемых стратегий развития образования детей, ведущих с родителями кочевой образ жизни, на основе лучшего зарубежного опыта и отечественных научных исследований.

\section{ЛИТЕРАТУРА}

1. Abdulrahman Y.M. (2016) Trends and Innovations in Education of Nigerian Nomadic Population - 2016 // doi: http: // dx.doi.org /10.14516 / fde.2016.014.020.020 , $21 \mathrm{p}$.

2. Aderinoye, R.A., Ojokheta, K.0., Olojede, A.A.. Integrating mobile learning into nomadic education programmes in Nigeria: issues and perspectives. The International Review of Research in Open and Distributed Learning. - 2007. - 8 (2) // http: // www.irrodl.org /index /php/irrodl /article /view /347/919

3. Amadi D.C. Nomadic education in Nigeria: using English to foster communal peace and enhance the education of herdsmen // Global Journal of Arts Humanities and Social Sciences - $2015-3(5)-16-21 \mathrm{p}$.

4. Anita Sharma. South Asian Nomads - A Literature Review // Create Pathways to Access : Research Monograph. - 2011. - № 58. Jan. - 51 p.

5. Booth T. Viewing inclusion from a distance: Gaining perspective from comparative study // Support for learning. - 1999. - 14 (4). - 164-168 p.

6. Гармаева И.Б. Монгольская цивилизация на пороге XXI века // Диаспоры в современном мире : материалы международного круглого стола. Улан-Удэ (15 октября 2007 г.); Хулун-Буйр (13 декабря 2007 г.). - Улан-Удэ : Изд-во Бурят.гос. ун-та, 2007.

7. Грайворонский В.В. Сравнительный анализ изменений в уровне жизни животноводов Монголии и Автономного района // Внутренняя Монголия /КНР/ в 1978-2000 гг. - Mongolica, 2005. - Vol. 16 (37). - C. 249-260.

8. Quicke Sara Prout, Green Charmaine. Mobile (nomadic) cultures and the politics of mobility: Insights from Indigenous Australia. - 2018. - 23 April // http://doi. org/10.1111/tran.12243

9. Жамбалова С.Г. Кочевой образ жизни в современном мире: проблемы традиционализма и модернизации // Ученые записки. - ЗабГГпу, 2012. - С.142149. 
10. Жуковская Н.Л. Кочевники Монголии: Культура. Традиции. Символика: учеб.пособие. - М.: Вост.лит., 2002. - 247 с.

11. Kraetli Saverio. Education provision to nomadic pastoralists // A literature review. - 2001. - $84 \mathrm{p}$.

12. Ng'asike, John Teria. Indigenous knowledge practices for sustainable lifelong education in pastoralist communities of Kenya // International Review of education. 2019. - Feb. - Volume 65(1). - pages 19-46 // D01: 10.1007/s11159-019-09767-4

13. Olaniran, Sunday Olawale. Almajiri education: Policy and practice to meet the learning needs of the nomadic population in Nigeria. - 2018. - Jan. - 111-126 p. // Doi.org/10.1007/s11159-018-9705-2

14. Promoting Educational Access for the Indigenous Reindeer Herders, Fishermen and Hunters in the Nomadic Schools of Yakutia, Russian Federation / RobbekV.A., Gabysheva F.V., Nikitina R.S., Sitnikova N.V // Traveller. Nomadic and Migrant Education/ Routledge Research in Education. - 2009. - 230 p.

15. Тойнби А.Дж. Исследование истории: Возникновение, рост и распад цивилизаций. - М.: АСТМОСКВА, 2009. - 670 с.

16. Use of radio an a nomadic education programme: Nigeria / UIL(UNESCO Institute for Lifelong Learning) (2008). // Effective literacy practices database. - Hamburg: UIL // http://litbase.uil.unesco.org. (Retrieved 18 Dec 2017)

( С Ситникова Наталья Васильевна (nsitni@rambler.ru), Николаева Алла Дмитриевна.

Журнал «Современная наука: актуальные проблемы теории и практики»

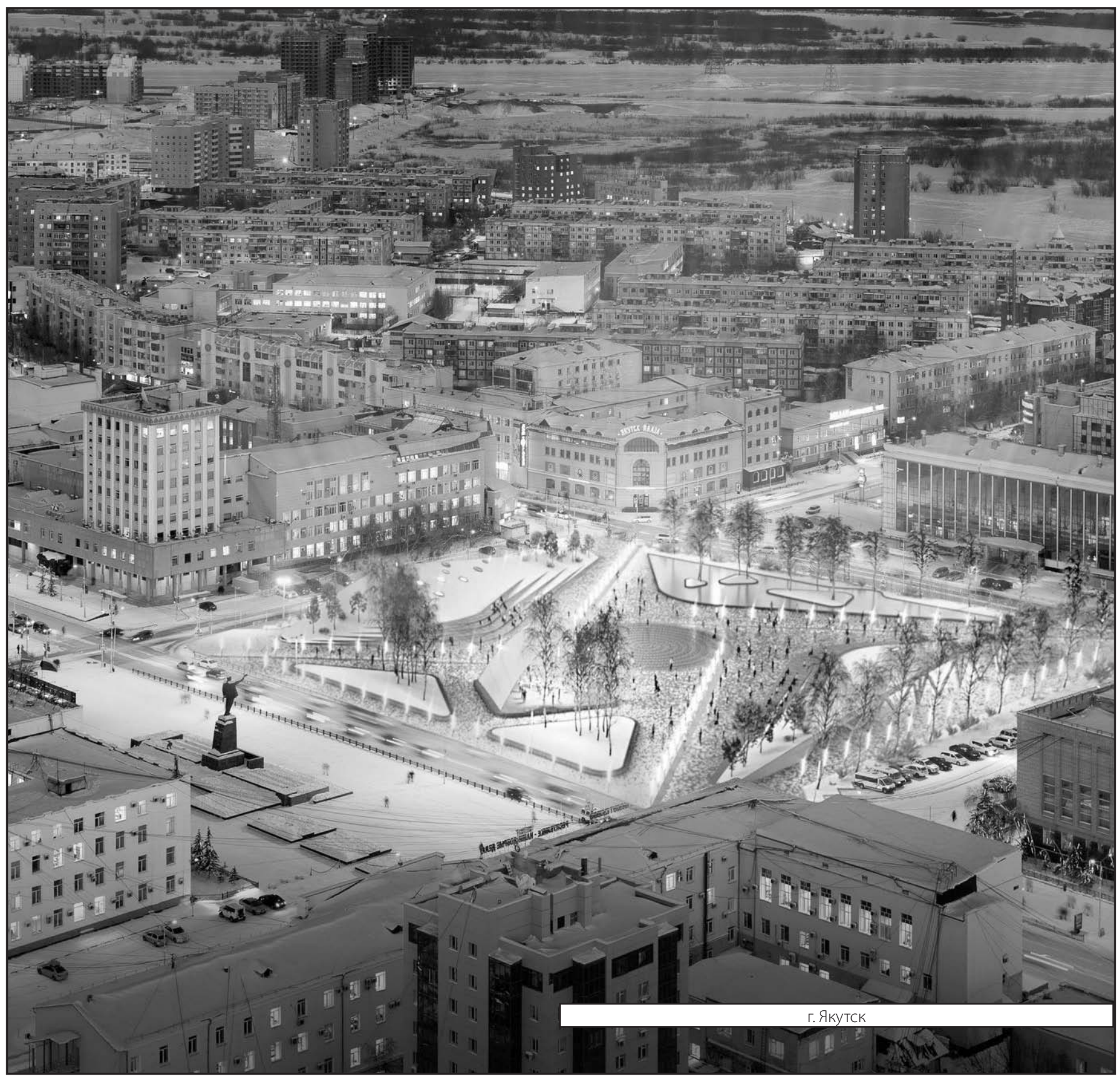

